\title{
The effect of resveratrol on oxidative ovary-damage induced by methotrexate in rats (Resveratrol oxidative ovary-damage)
}

\author{
Nahit Ata ${ }^{1}$, Nur G. Kulhan ${ }^{1}$, Mehmet Kulhan ${ }^{1}$, Can Turkler ${ }^{1}$, Tunay Kiremitli ${ }^{1}$, Sevil Kiremitli ${ }^{1}$, \\ Ferda Keskin Cimen ${ }^{2}$, Halis Suleyman ${ }^{3}$ and Veysel Toprak ${ }^{4}$ \\ ${ }^{1}$ Erzincan University Medical Faculty, Gynaecology and Obstetrics Department, Erzincan, Turkey \\ ${ }^{2}$ Erzincan University Medical Faculty, Medical Pathology, Erzincan, Turkey \\ ${ }^{3}$ Erzincan University Medical Faculty, Medical Pharmacology, Erzincan, Turkey \\ ${ }^{4}$ Lotus Hospital, Gynaecology and Obstetrics Department, Urfa, Turkey
}

\begin{abstract}
Methotrexate (MTX) is a commonly used folic acid antagonist for the treatment of neoplasia and some autoimmune diseases. Resveratrol has important anti-inflammatory, antioxidant and immunomodulatory properties. The aim of this study was to investigate the effects of resveratrol on MTX-induced ovary-damage and oxidative stress in rats. We hypothesized that supplement of resveratrol could counteract MTX-induced cytotoxicity in rat ovary. Albino Wistar female rats were randomly divided into three groups: Healthy control (HC), resveratrol + methotrexate (RMTX) and methotrexate (MTX) group. Their ovaries were removed. Biochemical and histopathological methods were utilized for evaluation of the oxidative ovary-damage. MDA was found to be higher but tGSH and SOD were lower in the ovarian tissue of the rat group administered MTX, but it is observed that these ratios are reversed in HC and in RMTX groups. MTX treatment induced ovary damage and especially pre-treatment with resveratrol provided protective effect against this MTXinduced ovary-damaged.
\end{abstract}

Key words: Methotrexate - Oxidative ovary-damage - Resveratrol

\section{Introduction}

Methotrexate (MTX) is a commonly used folic acid antagonist for the treatment of neoplasia and some autoimmune diseases. It inhibits deoxyribonucleic acid (DNA) synthesis and cell growth in actively proliferating cells, particularly malignant cells, trophoblasts and fetal cells (Boelens et al. 2018). The use of MTX can be associated with various adverse effects in the ovary in a wide range of severity; most risk of side effects is affected by the MTX dose and treatment regimen. The maturation of oocytes can be severely impaired due to MTX-induced DNA breakage, disruption of the spindle assembly, depletion of anti-oxidation enzymes and mitochondrial dysfunction. All of this can lead to an elevation of the intracellular reactive oxygen species (ROS) level, which means that an anti-oxidant supplement

Correspondence to: Mehmet Kulhan, Menderes Mah. 127. Sok, No: 7A D:7 Nar Konutları, Demirkent/ Erzincan, Turkey E-mail: Mehmet_kulhan@yahoo.com can prevent the detrimental effect of MTX on oocytes. Resveratrol, a natural polyphenolic, non-flavonoid antioxidant (trans-3, 40, 5-trihydroxystylben), is a phytoalexin which has high levels of food products, especially red wine made from grapes (Sayin et al. 2017). The antioxidant properties of plant extracts containing phenol group have been shown in previous studies (Burri et al. 2017; Zhang et al. 2018). Resveratrol has important anti-inflammatory, antioxidant and immunomodulatory properties (Soufi et al. 2012). Resveratrol has been shown to inhibit the synthesis of ROS, cyclooxygenase-2 (COX-2) and prostaglandin (PG) in various experimental models, and thus its anti-inflammatory effects have been demonstrated (Erbas et al. 2014). On the basis of this background, as measuring of the oxidative stress parameters by biochemical methods and histopathologically, we aimed to investigate the effect of resveratrol on oxidative ovary damage induced by methotrexate in an experimental rat model. We investigated whether addition of resveratrol could prevent MTX-induced cytotoxicity in rat ovary. 


\section{Materials and Methods}

\section{Animals}

The recommendations of the Declaration of Helsinki (1964) for animal care were taken into consideration. The experiments were performed in agreement with the "Principles of laboratory animal care" (NIH publication no. 86-23, revised 1985). For the experiment, a total of 18 albino Wistar female rats weighing between 250-265 g were used. The rats were provided by the Medical Experimental Practice and Research Center of Ataturk University. The animals were kept in room temperature $\left(22^{\circ} \mathrm{C}\right)$ in groups and were fed ad libitum. Animal experiments were performed in accordance with the National Guidelines for the Use and Care of Laboratory Animals and were approved by the local animal ethics committee of Ataturk University Erzurum, Turkey (Ethics Committee Number: 1800109500 Dated: 04.04.2018).

\section{Chemical substances}

The thiopental sodium used in the experiment was provided by Ibrahim Etem Ulagay (Istanbul, Turkey); resveratrol was supplied from Sigma, methotrexate was provided MedDrug-Turkey.

\section{Experiment groups}

The rats used in this study were divided into three groups: Healthy control (HC), Resveratrol + Methotrexate (RMTX) and Methotrexate (MTX) group.

\section{Experiment procedure}

All procedures followed were in accordance with the ethical standards of the responsible committee on human experimentation (institutional and national) and with the Helsinki Declaration of 1975, as revised in 2008 Informed consent was obtained from all patients for being included in the study.

RMTX group was given resveratrol $25 \mathrm{mg} / \mathrm{kg}(n=6)$ while MTX and HC groups were orally administered distilled water as the solvent by gavage because resveratrol has been shown to be effective in animals at doses ranging from 10 to $25 \mathrm{mg} / \mathrm{kg}$ in published literatüre (Arslan et al. 2015). One hour after resveratrol and distilled water was administered, RMTX and MTX rat groups were injected with $2 \mathrm{mg} / \mathrm{kg}$ methotrexate intraperitoneally (i.p.). The average dose of methotrexate to produce oxidative stress in rats is $10-50 \mathrm{mg} / \mathrm{kg}$ (Omer et al 2014; Yucel et al. 2017). This procedure was repeated once a day for 30 days. At the end of the period, six rats from each group were sacrificed using high-dose anesthetic ( $50 \mathrm{mg} / \mathrm{kg}$ of thiopental i.p.).
Their ovaries were removed, and the levels of malondialdehyde (MDA), total gluthatione (tGSH), superoxide dismutase (SOD) were measured. The tissues were also histopathologically researched. The results obtained from the RMTX group were compared with the results obtained from the HC and MTX groups.

\section{Preparing the sample}

Rat ovaries were kept in $-80^{\circ} \mathrm{C}$ for 3 days to determine tissue SOD enzyme activity and tGSH and MDA levels. To prepare the tissue homogenates, the ovaries tissues were ground with liquid nitrogen in a mortar; $0.1 \mathrm{~g}$ was weighed and then treated with $4.5 \mathrm{ml}$ of an appropriate buffer. The tissues were treated with HEPES buffer for SOD and RIPA buffer for MDA measurement and then homogenized on ice by an Ultra-Turrax homogenizer at 9500 rpm. Homogenates were filtered and centrifuged by using a refrigerator centrifuge at $4^{\circ} \mathrm{C}$. These supernatants were then used to determine SOD and MDA levels with highly sensitive ELISA kits (Cayman Chemical, Cell Biolabs Oxi Select ${ }^{\mathrm{Tm}}$ TBARS Assay STA-330 Kit, respectively). Kits were specifically designed for rat cytokines, and all measurements were performed according to the manufacturers' instructions. Cytokine assays for each animal and its correlated control were run in the same lot. All assays were carried out at room temperature in dublicate.

\section{Superoxide dismutase (SOD) analysis}

Measurements were performed according to the method of Sun et al. (1988). When xanthine is converted into uric acid by xanthine oxidase, SOD forms. If nitro blue tetrazolium (NBT) is added to this reaction, SOD reacts with NBT and a purple-colored formazan dye occurs. The sample was weighed and homogenized in $2 \mathrm{ml}$ of $20 \mathrm{mmol} / \mathrm{l}$ phosphate buffer containing $10 \mathrm{mmol} / \mathrm{l}$ EDTA at $\mathrm{pH}$ 7.8.

The sample was centrifuged at $6000 \mathrm{rpm}$ for 10 minutes and than the brilliant supernatant was used as assay sample. The measurement mixture containing $2450 \mu \mathrm{l}$ measurement mixture $(0.3 \mathrm{mmol} / \mathrm{l}$ xanthine, $0.6 \mathrm{mmol} / \mathrm{l} \mathrm{EDTA}, 150 \mu \mathrm{mol} / \mathrm{l}$ NBT, $0.4 \mathrm{~mol} / 1 \mathrm{Na}_{2} \mathrm{CO}_{3}, 1 \mathrm{~g} / \mathrm{l}$ bovine serum albumin), $500 \mu \mathrm{l}$ supernatant and $50 \mu \mathrm{l}$ xanthine oxidase $(167 \mathrm{U} / \mathrm{l})$ was vortexed. Then it was incubated for $10 \mathrm{~min}$. At the end of the reaction, formazan occured. The absorbance of the purple-colored formazan was measured at $560 \mathrm{~nm}$. As more of the enzyme exists, the least $\mathrm{O}_{2}$ - radical that reacts with NBT occurs.

\section{Malondialdehyde (MDA) analysis}

The concentrations of ovarian mucosal lipid peroxidation were determined by estimating MDA using the thiobar- 
bituric acid test (Ohkawa et al. 1979). $0.5 \mathrm{ml}$ homogenate was added to a solution containing $0.2 \mathrm{ml}$ of $80 \mathrm{~g} / \mathrm{l}$ sodium lauryl sulfate, $1.5 \mathrm{ml}$ of $200 \mathrm{~g} / \mathrm{l}$ acetic acid, $1.5 \mathrm{ml}$ of $8 \mathrm{~g} / \mathrm{l}$ of 2-thiobarbiturate, and $0.3 \mathrm{ml}$ of distilled water. The mixture was incubated at $98^{\circ} \mathrm{C}$ for $1 \mathrm{~h}$. Upon cooling, $5 \mathrm{ml}$ of n-butanol: pyridine (15:1) was added. The mixture was vortexed for $1 \mathrm{~min}$ and centrifuged for $30 \mathrm{~min}$ at $4000 \mathrm{rpm}$. The absorbance of the supernatant was measured at 532 nm. The standard curve was obtained by using 1,1,3,3-tetramethoxypropane.

\section{Total glutathione (tGSH) analysis}

The amount of GSH in the total homogenate was measured according to the method of Sedlak and Lindsay (1968) with some modifications. The sample was weighed and homogenized in $2 \mathrm{ml}$ of $50 \mathrm{mmol} / \mathrm{l}$ Tris- $\mathrm{HCl}$ buffer containing $20 \mathrm{mmol} / \mathrm{l}$ EDTA and $0.2 \mathrm{mmol} / \mathrm{l}$ sucrose at $\mathrm{pH}$ 7.5. The homogenate was immediately precipitated with $0.1 \mathrm{ml}$ of $25 \%$ trichloroacetic acid, and the precipitate was removed after centrifugation at $4200 \mathrm{rpm}$ for $40 \mathrm{~min}$ at $4^{\circ} \mathrm{C}$ and the supernatant was used to determine GSH level.

A total of $1500 \mu \mathrm{l}$ of measurement buffer $(200 \mathrm{mmol} / \mathrm{l}$ Tris-HCl buffer containing $0.2 \mathrm{mmol} / \mathrm{l} \mathrm{EDTA}$ at $\mathrm{pH} 7.5$ ), $500 \mu \mathrm{l}$ supernatant, $100 \mu \mathrm{l}$ DTNB $(10 \mathrm{mmol} / \mathrm{l})$ and $7900 \mu \mathrm{l}$ methanol were added to a tube and vortexed and incubated for $30 \mathrm{~min}$ in $37^{\circ} \mathrm{C}$. 5,5-Dithiobis (2-nitrobenzoic acid) (DTNB) was used as an chromogen and it formed a yellowcolored complex with sulfhydry groups. The absorbance was measured at $412 \mathrm{~nm}$ using a spectrophotometer (Beckman DU 500, USA). The standard curve was obtained by using reduced glutathione.

\section{Histological examination}

Histological examination was performed at the pathology department of University Hospital. Following dehydration of the excised ovaries and embedment in paraffin blocks, 4-6 mm slices were prepared and stained with hematoxylin and eosin. The specimens were evaluated under light microscopy simultaneously by two experienced histopathologists. Ovarian damage; including follicular cell degeneration, vascular congestion, hemorrhage, and inflammation (neutrophil infiltration), was evaluated histologically

\section{Statistical analysis}

Statistical analyses were carried out using the Statistical Package for Social Sciences, Windows version 18.0 (SPSS, Chicago, IL, USA). Descriptive statistics for each variable were determined. Normality of the data distribution was assessed with the Kolmogorov-Smirnov test. Results for continuous variables were demonstrated as mean \pm standard error of the mean (mean \pm SEM). Significance of differences between the groups was determined using oneway ANOVA test followed by Fisher's post-hoc LSD (least significant differences) analysis. $p$ value less than 0.05 was considered significant.

\section{Results}

\section{Biochemical results}

MDA was found to be higher in the ovarian tissue of the MTX-treated rat group, whereas tGSH and SOD were found to be lower. As is seen in the Figure 1, resveratrol prevented the increasing of MDA, on the other hand, it also prevented the decreasing of tGSH and SOD levels. Resveratrol and MTX have been found to affect the levels of these oxidants and antioxidants in ovary Table 1 . There are the differences between the MTX, RMTX and HC group in terms of the amount of tGSH, SOD and MDA that were statistically significant (Table 1).

\section{Histopathological results}

The normal histopathological sections of the ovarian tissue of $\mathrm{HC}$ rats are shown in Figure 2A. Histopathological sec-

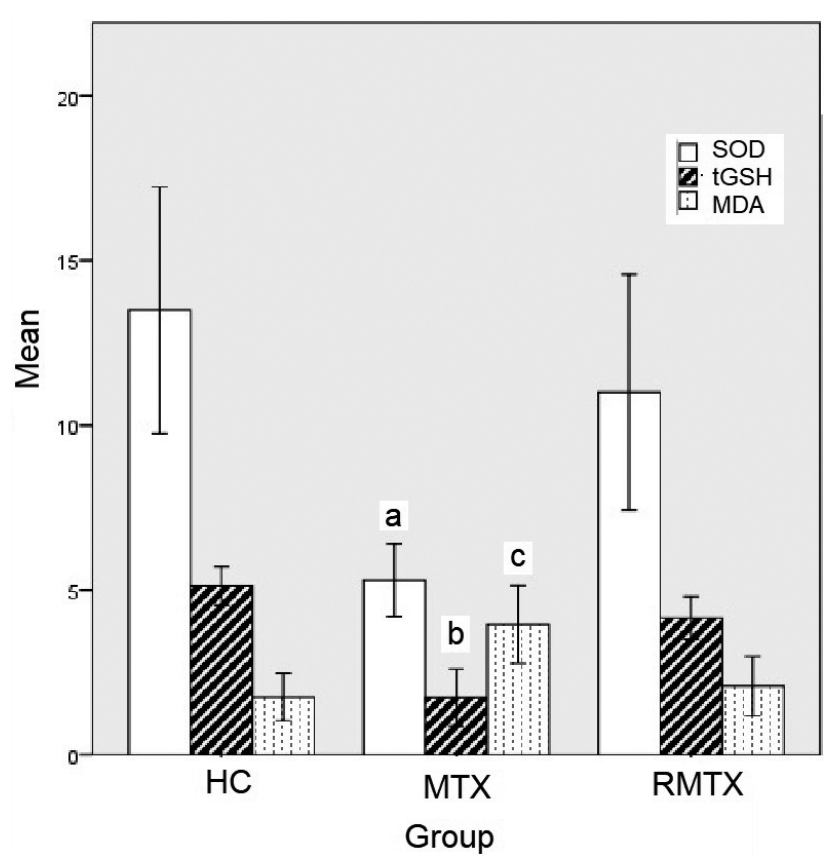

Figure 1. Superoxide dismutase (SOD), total glutathione (tGSH) and malondialdehyde (MDA) levels between groups. Data are mean $\pm \mathrm{SD} .{ }^{\mathrm{a}} p=0.032,{ }^{\mathrm{b}} p=0.001,{ }^{\mathrm{c}} p=0.464$ vs. corresponding value of HC group. HC, healthy control; MTX, methotrexate; RMTX, resveratrol + methotrexate. 
Table 1. Effect of MTX or its combination with resveratrol on levels of ovary MDA, tGSH and SOD activities in rats

\begin{tabular}{lccc}
\hline Group & $\begin{array}{c}\text { SOD } \\
(\mathrm{U} / \mathrm{g})\end{array}$ & $\begin{array}{c}\text { tGSH } \\
(\mathrm{nmol} / \mathrm{g})\end{array}$ & $\begin{array}{c}\text { MDA } \\
(\mu \mathrm{mol} / \mathrm{g})\end{array}$ \\
\hline HC & $13.5 \pm 1.8708$ & $5.117 \pm 0.2927$ & $1.750 \pm 0.3619$ \\
MTX & $5.3 \pm 0.5514^{\mathrm{a}}$ & $1.733 \pm 0.4320^{\mathrm{b}}$ & $3.950 \pm 0.5891^{\mathrm{c}}$ \\
RMTX & $11 \pm 1.7889$ & $4.150 \pm 0.3271$ & $2.083 \pm 0.4491$ \\
\hline
\end{tabular}

Data are mean $\pm \mathrm{SD} .{ }^{\mathrm{a}} p=0.032,{ }^{\mathrm{b}} p=0.001,{ }^{\mathrm{c}} p=0.464$ vs. corresponding value of HC group. HC, healthy control; MTX, methotrexate; RMTX, resveratrol + methotrexate; SOD, superoxide dismutase; tGSH, total glutathione; MDA, malondialdehyde.

tions of ovarian tissue of MTX group are shown in Figure 2B. We a marked degenerative secondary follicle (double sided arrow), severe hemorrhage (striated arrow), marked edema (straight arrow) and marked dilate conjunctival blood vessels
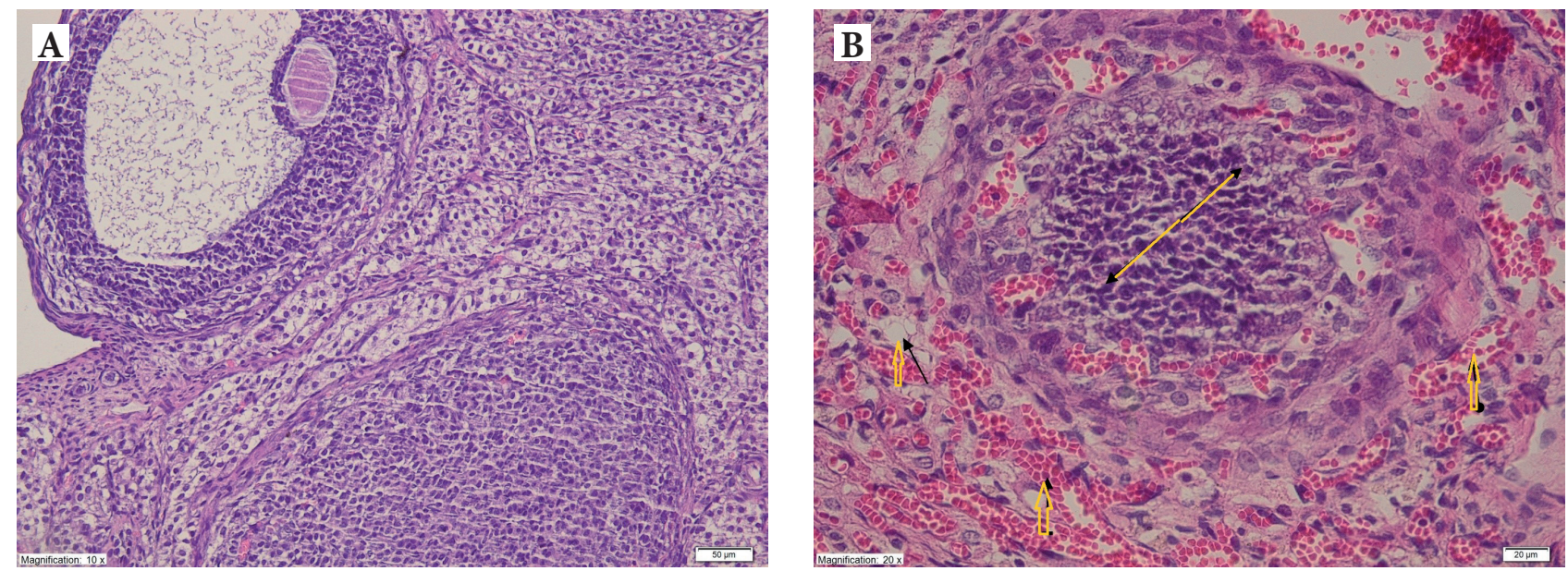

(round arrow) (Figure 2B). On the other hand, in RMTX ovarian tissues, no pathological findings were found except histopathologically dilated conjunctival blood vessels (plain arrow) (Figure 2C).

\section{Discussion}

Resveratrol is a molecule with antioxidant properties (Firouzi et al. 2015). Although there is no information about the protective effect of resveratrol on MTX-induced damage in the literature search, there are a few studies in the literature showing that resveratrol suppresses oxidative stress caused by MTX in various tissues (Dalaklioglu et al. 2013). In this study, we have carried out various biological experiments on oxidative damage and determined that antioxidant resveratrol may protect the ovary from the damage effect of MTX.

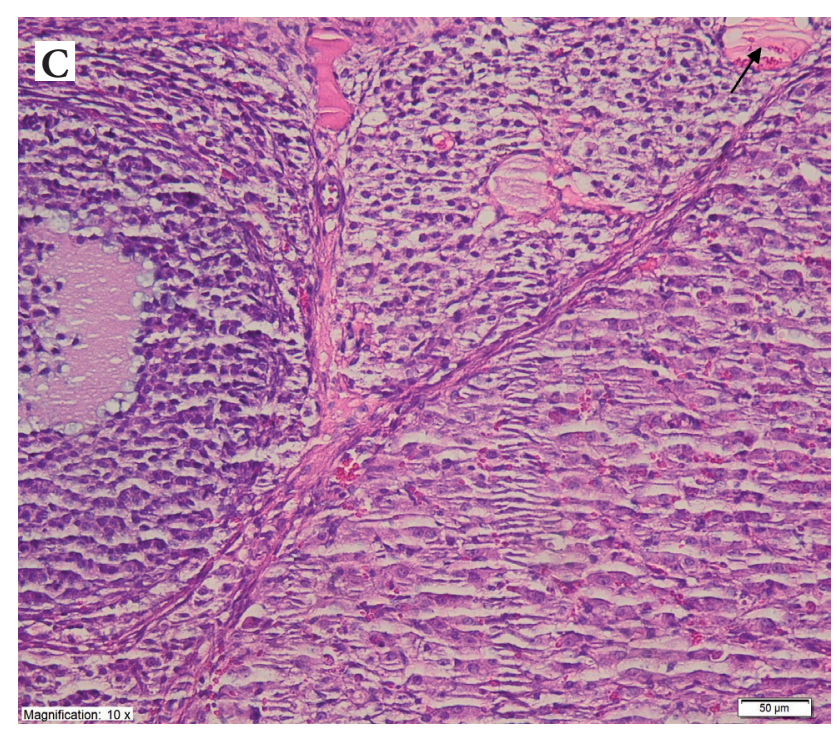

Figure 2. A. Normal histopathologic appearance is observed in overgrowth of HC group $(\mathrm{H} \& \mathrm{E}, \times 200)$. B. In MTX group (given methotrexate alone), significant degenerative secondary follicles (double-sided arrow), severe hemorrhage (striated arrow), marked edema (smooth arrow) and marked dilate conjunctival blood vessels are seen $(\mathrm{H} \& \mathrm{E}, \times 400)$. C. In the RMTX group (treated with resveratrol and methotrexate), no pathologic findings were found except histopathologically dilated conjunctival blood vessels (plain arrow) (H\&E, ×200). (For abbreviations, see Fig. 1). 
Oxidative stress is the deterioration of the balance between oxidants and antioxidants. In vivo, MDA acts as an oxidant, tGSH and SOD as antioxidant. In our study, MDA levels were found to be higher in the ovarian tissues of the rats given MDA and the levels of TGSH and SOD were lower. On the other hand; lower MDA, but higher tGSH and SOD levels were observed in ovaries of rats treated with resveratrol compared to MTX group.

ROS have important roles in ovulation physiology (Agarwal and Allamaneni 2004). However, excessive ROS in pathological conditions may cause oxidative stress. Scientific efforts focus on ROS as an important role in linking diabetes, aging and other diseases with weak oocytes. MTX can produce autoxidation-induced ROS, and may further modify some enzymes, such as SODs, glutathione peroxidases, and glutathione transferases, leading to reduced antioxidant defense pathways (Howard et al. 2016). In recent days, studies have been conducted to investigate the protective antioxidant effect of resveratrol on female reproductive system. Previous studies have shown that resveratrol treatment during in vitro oocyte maturation has beneficial effects (Kwak et al. 2012; Ozgur et al. 2018). Furthermore, resveratrol is protected against aging by decreasing fertility of mice (Liu et al. 2013). All of these protective effects relate to the capabilities of resveratrol to eliminate cellular excess ROS. In our study, resveratrol reduced MTX-induced ROS (Fig. 1 and Table 1). We evaluated resveratrol as the essence of its protective effect against damage caused by MTX-induced ovary.

In this study, we observed MTX-induced ROS accumulations consistent with observed MDA increase and decreased SOD and tGSH in rat ovaries. These findings showed that MTX increased oxidative stress in rat ovary. ROS accumulation is known to inhibit nuclear and cytoplasmic maturation and lead to cell death (Tatemoto et al. 2000).

Resveratrol developed the previously proposed mouse oocyte antioxidant system (Liu et al. 2013). As a polyphenol, resveratrol can clean ROS in oocytes with a phenolic hydroxyl group. In addition, resveratrol may also protect the embryo against nicotine-induced oxidative stress (Lin et al. 2012). In this study, resveratrol was found to protect the ovary from damage caused by MTX; this has been demonstrated by decreased MDA and increased SOD, tGSH levels (Fig. 1, Table 1).

The short length of the estrous cycle of rats makes them ideal for investigation of changes occurring during the reproductive cycle. The estrous cycle lasts four days and is characterized as: proestrus, estrus, metestrus and diestrus, which may be determined according to the cell types observed in the vaginal smear (Long and Evans 1922; Freeman 1988). In our study, the relationship between follicle histology and cycle phases could not be evaluated because vaginal smear was not taken. this is one of the limitations of our study.
Our work has some limitations. First, the results of experimental studies on laboratory animals may not be assigned to humans. Therefore, our study needs to be verified in humans in future studies. In addition, our results could be confirmed by using of agents that are more toxic to the ovary, for example, cyclophosphamide, which is more toxic, may be chosen instead of MTX.

\section{Conclusion}

It has been shown that MTX treatment induces ovarian damage and, in particular, pretreatment with resveratrol provides a protective effect against this MTX-induced ovarian damage. However, there is a need for further studies, including human trials, before making a definitive statement about the potential benefit of resveratrol in addition to MTX treatment.

Conflict of interest. The authors declare that they have no conflict of interest.

\section{References}

Agarwal A, Allamaneni SS (2004): Role of free radicals in female reproductive diseases and assisted reproduction. Reprod. Biomed. Online 9, 338-347

https://doi.org/10.1016/S1472-6483(10)62151-7

Arslan A, Ozcicek F, Keskin Cimen F, Altuner D, Yarali O, Kurt N Tumkaya L, Ozturk C, Suleyman H.(2015): Protective effect of resveratrol against methotrexate-induced oxidative stress in the small intestinal tissues of rats. Int. J. Clin. Exp. Med. 15, 10491-10500

Boelens AD, Mathôt RAA, Vlaar APJ, Bouman CSC (2018): Glucarpidase treatment for methotrexate intoxication: a case report and review of the literature. Neth. J. Med. 76, 36-39

Burri SCM, Ekholm A, Håkansson Å, Tornberg E, Rumpunen K (2017): Antioxidant capacity and major phenol compounds of horticultural plant materials not usually used. J. Funct. Foods 38, 119-127 https://doi.org/10.1016/j.jff.2017.09.003

Dalaklioglu S, Genc GE, Aksoy NH, Akcit F and Gumuslu S (2013): Resveratrol ameliorates methotrexate-induced hepatotoxicity in rats via inhibition of lipid peroxidation. Hum. Exp. Toxicol. 32, 662-671 https://doi.org/10.1177/0960327112468178

Erbas O, Pala HG, Pala EE, Oltulu F, Aktug H, Yavasoglu A, Taşkıran D (2014): Ovarian failure in diabetic rat model: nuclear factorkappaB, oxidative stress, and pentraxin-3. Taiwan J. Obstet. Gynecol. 53, 498-503 https://doi.org/10.1016/j.tjog.2013.11.008

Firouzi F, Khoei S, Mirzaei HR (2015): Role of resveratrol on the cytotoxic effects and DNA damages of iododeoxyuridine and megavoltage radiation in spheroid culture of U87MG glioblastoma cell line. Gen. Physiol. Biophys. 34, 43-50 https://doi.org/10.4149/gpb_2014023 
Freeman, ME. (1988): The ovarian cycle of the rat. In: Physiology of Reproduction. (Eds. E Knobil, J Neil), pp. 1893-1928. Raven Press Ltd., New York

Howard SC, McCormick J, Pui CH Buddington RK, Harvey RD (2016): preventing and managing toxicities of high-dose methotrexate. Oncologist 21, 1471-1482 https://doi.org/10.1634/theoncologist.2015-0164

Kwak SS, Cheong SA, Jeon Y, Lee E, Choi KC, Jeung EB, Hyun SH (2012): The effects of resveratrol on porcine oocyte in vitro maturation and subsequent embryonic development after parthenogenetic activation and in vitro fertilization. Theriogenology 78, $86-101$ https://doi.org/10.1016/j.theriogenology.2012.01.024

Lin C, Yon JM, Jung AY. Lee JG, Jung KY, Kang JK (2012): Resveratrol prevents nicotine-induced teratogenesis in cultured mouse embryos. Reprod. Toxicol. 34, 340-346 https://doi.org/10.1016/j.reprotox.2012.05.097

Liu M, Yin Y, Ye X, Zeng M, Zhao Q, Keefe DL, Liu L (2013): Resveratrol protects against age-associated infertility in mice. Hum. Reprod. 28, 707-717 https://doi.org/10.1093/humrep/des437

Long JA, Evans HM (1922): The estrous cycle in the rat and its associated phenomena. Memories of University of California 6, 1-148

Ohkawa H, Ohishi N, Yagi K (1979): Assay for lipid peroxides in animal tissues by thiobarbituric acid reaction. Anal. Biochem. 95, 351-358 https://doi.org/10.1016/0003-2697(79)90738-3

Omer EY, Bunyamin B, Mehmet IT, Mine G, Suleyman S (2014): The effect of mirtazapine on methotrexate-induced oxidative damage and infertility in rats. ScienceAsia 40, 152-156 https://doi.org/10.2306/scienceasia1513-1874.2014.40.152

Ozgur S, Oktem M, Altinkaya SO, Oktem EO, Cenksoy C, Erdem O, Elbeg S, Helvaci A, Erdem A, Erdem M (2018): The effects of resveratrol on ovarian hyperstimulation syndrome in a rat model. Taiwan J. Obstet. Gynecol. 57. 383-388 https://doi.org/10.1016/j.tjog.2018.04.010

Sayin O, Micili SC, Goker A, Kamaci G, Ergur BU, Yilmaz O, Akdogan GG (2017): The role of resveratrol on full - Thickness uterine wound healing in rats. Taiwan J. Obstet. Gynecol. 56, 657-663 https://doi.org/10.1016/j.tjog.2017.08.015

Sedlak J, Lindsay RH (1968): Estimation of total, protein-bound, and nonprotein sulfhydryl groups in tissue with Ellman's reagents. Anal. Biochem. 25, 192-205 https://doi.org/10.1016/0003-2697(68)90092-4

Soufi FG, Vardyani M, Sheervalilou R, Mohammadi M, Somi MH (2012): Long-term treatment with resveratrol attenuates oxidative stress pro-inflammatory mediators and apoptosis in streptozotocin-nicotinamide-induced diabetic rats. Gen. Physiol. Biophys. 31, 431-438 https://doi.org/10.4149/gpb_2012_039

Sun Y, Oberley LW, Li Y (1988): A simple method for clinical assay of superoxide dismutase. Clin. Chem. 34, 497-500

Tatemoto H, Sakurai N, Muto N (2000): Protection of porcine oocytes against apoptotic cell death caused by oxidative stress during In vitro maturation: role of cumulus cells. Biol. Reprod. 63, $805-810$ https://doi.org/10.1095/biolreprod63.3.805

Yucel Y, Oguz E, Kocarslan S, Tatli F, Gozeneli O, Seker A, Sezen H, Buyukaslan H, Aktumen A, Ozgonul A ,et al. (2017): The effects of lycopene on methotrexate-induced liver injury in rats. Bratisl. Lek. Listy 118, 212-216 https://doi.org/10.4149/BLL_2017_042

Zhang Y, Pechan T, Chang SKC (2018): Antioxidant and angiotensin-I converting enzyme inhibitory activities of phenolic extracts and fractions derived from three phenolic-rich legume varieties. J. Funct. Foods 42, 289-297 https://doi.org/10.1016/j.jff.2017.12.060

Received: April 11, 2019

Final version accepted: July 23, 2019 